\title{
1 Global determinants of the distribution of insect 2 genetic diversity
}

3 Authors: Connor M French ${ }^{1,2^{*}}$, Laura D Bertola ${ }^{1,3}$, Ana C Carnaval ${ }^{1,2}$, Evan P Economo ${ }^{4}$, Jamie $4 \mathrm{M} \mathrm{Kass}^{4}$, David J Lohman ${ }^{1,2,5}$, Katharine A Marske ${ }^{6}$, Rudolf Meier ${ }^{7,8}$, Isaac Overcast ${ }^{2,9,10}$,

5 Andrew J. Rominger ${ }^{11,12}$, Phillip Staniczenko ${ }^{13}$, and Michael J Hickerson 1,2,14

$6 \quad{ }^{1}$ Department of Biology, City College of New York, New York, New York, USA

$7 \quad{ }^{2}$ Biology Ph.D. Program, The Graduate Center, City University of New York, New York, New

8 York, USA

$9{ }^{3}$ Section for Computational and RNA Biology, Department of Biology, University of

10 Copenhagen, Copenhagen N 2200, Denmark

$11{ }^{4}$ Biodiversity and Biocomplexity Unit, Okinawa Institute of Science and Technology, Onna,

12 Okinawa, JAPAN, 904-0495

$13{ }^{5}$ Entomology Section, National Museum of Natural History, Manila, Philippines

$14{ }^{6}$ Department of Biology, University of Oklahoma, Norman, Oklahoma, USA

$15 \quad{ }^{7}$ Humboldt University, Berlin, Germany

$16{ }^{8}$ Museum für Naturkunde, Berlin, Germany

$17{ }^{9}$ Institut de Biologie de l'Ecole Normale Superieure, Paris, France

$18{ }^{10}$ Department of Vertebrate Zoology, American Museum of Natural History, New York, New

19 York, USA

$20{ }^{11}$ School of Biology and Ecology, University of Maine, Orono, ME, USA

$21{ }^{12}$ Maine Center for Genetics in the Environment, University of Maine, Orono, ME, USA

$22{ }^{13}$ Department of Biology, Brooklyn College, Brooklyn, New York, USA

$23{ }^{14}$ Division of Invertebrate Zoology, American Museum of Natural History, New York, New York, 24 USA

*email: cfrench@gradcenter.cuny.edu

\section{Abstract}

28 Understanding global patterns of genetic diversity (GD) is essential to describe, monitor, and

29 preserve the processes giving rise to life on Earth. To date, efforts to map macrogenetic

30 patterns have been restricted to vertebrate groups that comprise a small fraction of Earth's

31 biodiversity. Here, we construct the first global map of predicted insect genetic diversity. We

32 calculate the global distribution of GD mean (GDM) and evenness (GDE) of insect

33 assemblages, identify the global environmental correlates of insect GD, and make predictions 
34 for undersampled regions. Based on the largest and most species-rich single-locus genetic

35 dataset assembled to date, we find that both GD metrics follow a bimodal latitudinal gradient,

36 where GDM and GDE correlate with contemporary climate variation. Our models explain 1/4

37 and 1/3 of the observed variation in GDM and GDE in insects, respectively, making an important

38 step towards describing global biodiversity patterns in the most diverse animal taxon.

\section{Introduction}

Describing global patterns of biodiversity is essential for understanding and protecting processes governing the distribution of life across the world. To date, such global-scale assessments have largely focused on species richness ${ }^{1}$, phylogenetic diversity ${ }^{2,3}$, species abundances $^{4,5}$, and functional trait diversity ${ }^{6,7}$. These macroecological metrics have long been used to inform conservation and gain insights into mechanisms underlying eco-evolutionary patterns. Only recently, however, have the advances in high-throughput DNA metabarcoding been utilized for global studies of biodiversity ${ }^{8-11}$. original use as a tool for identifying and delimiting species. They aid in identifying adaptive potential and ecosystem resilience to disturbance ${ }^{13}$, and more generally, help to understand

50 how intraspecific variation can help support critical ecological functions ${ }^{14}$. Along with being an

51 important new component of the macroecological toolbox for conservation action ${ }^{15,16}$, the

52 promise of these eco-evolutionary insights is fueling the rise of the emerging field of

53 "macrogenetics" 17,18. Macrogenetic studies summarize the geographic distribution of average

54 intraspecific genetic variation across species assemblages to find previously unknown patterns 55 and processes underlying the generation and maintenance of biodiversity ${ }^{19}$. 
58 diversity ${ }^{20,21}$, while documenting latitudinal gradients in aggregated genetic diversity ${ }^{22-24}$.

59 Macrogenetic studies have also provided mixed support for the general influence of human disturbance on genetic diversity ${ }^{20,22,25,26}$, while climate stability ${ }^{20,26}$ and species' range sizes ${ }^{27}$

61 have been shown to influence intraspecific genetic diversity on a global scale.

The existing bias toward vertebrate macrogenetics leaves undocumented the bulk of the planet's animal biodiversity: insects. Insects are vital for maintaining critical ecosystem services

64 and functions ${ }^{28,29}$, yet to date insect macrogenetic studies have been restricted to the regional

65 scale due to the immense effort required to collect, identify, and sequence such a speciose

66 taxon ${ }^{30-33}$. There also is little agreement as to what extent insect communities are resilient to 67 global change ${ }^{34,35}$, including biological invasions ${ }^{36,37}$, habitat conversion ${ }^{38}$, and climate change

$68 \quad 39$. Here, we present the first global macrogenetic analysis of this large group, which is especially important given increasing evidence that many insect taxa may be in global decline with respect to occurrence, local richness, abundance and biomass ${ }^{35,40-46}$.

Unlike for most terrestrial vertebrates, comprehensive knowledge of species diversity,

72 distributions, and population dynamics are poorly known for most large insect groups ${ }^{47,48}$.

73 These constraints on understanding broad-scale insect biodiversity patterns point to a need for

74 a systematic global data synthesis ${ }^{49}$. One basic challenge for insects is the species

75 identification bottleneck underpinning large-scale biodiversity surveys that use conventional

76 morphological methods ${ }^{50,51}$. DNA barcoding and environmental DNA metabarcoding represent

77 viable approaches for expedited, large-scale, global quantification of insect species diversity ${ }^{52}$,

78 despite some known limitations ${ }^{53,54}$.

Most macrogenetic studies of animal taxa are based on mitochondrial DNA (mtDNA)

80 sequence data, which represent the majority of available sequences ${ }^{17}$. Despite the limitations of

81 using a single-locus marker ${ }^{55-58}$, the pragmatic advantages of the ability to sample the genetic

82 diversity of hundreds or thousands of taxa per locale potentially outweigh these considerations

8359,60 . The Barcode of Life Consortium database (BOLD) is a rich source of single-locus mtDNA 
84 that links quality-controlled genetic data with georeferenced metadata ${ }^{8}$. Leveraging this

85 resource, we compiled the largest macrogenetic dataset ever assembled: over 2.3 million

86 globally distributed and georeferenced mtDNA sequences (cytochrome c oxidase 1 - COI) for

87 over 95,000 operational taxonomic units (OTUs). We use these data to generate the first global

88 map of insect genetic variation using both the commonly used genetic diversity mean (GDM)

89 and a new measure we introduce: genetic diversity evenness (GDE). While GDM describes the

90 magnitude of average genetic diversity among species, GDE represents the shape of the

91 distribution of individual GD measures for all focal taxa that co-occur in a given area.

92 Considering both these values gives us the ability to discriminate between important processes

93 underlying community assembly and structure ${ }^{61}$. As macrogenetic studies to date only describe

94 average intraspecific genetic diversity (GDM), they are unable to determine whether high

95 metrics of genetic diversity are due to high diversity within most community members or to the

96 effects of a few taxa with extremely high diversity (Fig. 1; see Methods).

We focus our analyses on several questions about the macrogenetics of insects. First,

98 we evaluate whether the magnitude and variability of GD generally follows latitudinal trends of

99 increasing insect species richness in the tropics ${ }^{62,63}$. Explanations for this general latitudinal

100 gradient are often explained in terms of the wet tropics being either "museums" or conversely

101 "cradles", with opposite predictions with regards to range sizes ${ }^{64}$. If geographic range size

102 tends to correlate with $\mathrm{GD}^{65}$, we might expect this gradient given the "museum" hypothesis that

103 predicts that taxa in the tropics will be older, and have larger geographic range sizes ${ }^{66,67}$, In

104 contrast, species richness and GD may be decoupled due to the "cradle" hypothesis that

105 predicts higher speciation rates, more population structure, and smaller range sizes leading to

106 Rapoport's Rule ${ }^{68}$, the tendency for species' range sizes to increase with increasing latitude

10769,70 . Second, we might predict that the influence of Late Quaternary climate fluctuations to have

108 an impact on GD through population demographic processes influenced by cyclical variation in

109 precipitation, temperature, and glaciation patterns ${ }^{71,72}$, where areas with more stable climatic 
110 histories are predicted to have increased GD ${ }^{72}$. Finally, we consider the influence of human

111 disturbance on patterns of assemblage-wide GD, which we expect to decrease in magnitude in

112 areas of high human influence ${ }^{42}$.

113 To answer these questions, we explore how well insect GDM and GDE are predicted by

114 current and historical climate, habitat, and human disturbance. We first find environmental

115 correlates of intraspecific insect genetic diversity globally using Bayesian generalized linear

116 mixed models (GLMM), and then use these to predict patterns of insect GDM and GDE in

117 undersampled regions, which includes most of the planet. In contrast to most global vertebrate

118 biodiversity patterns documented to date, we find that insect GDM and GDE have bimodal

119 latitudinal gradients that peak in mid-latitude regions and that both metrics are positively

120 correlated with high temperature extremes.

\section{Results}

122 GDM and GDE were calculated from native-range insects sampled within raster grid cells at a

$123193 \mathrm{~km} \times 193 \mathrm{~km}$ equal-area resolution. These cells were heterogeneously distributed across

124 the globe on every continent except Antarctica ( $N=187$, Fig. 2). Regions with both high GDM

125 and high GDE (above the 90th percentile) were found in eastern North America as well as in the

126 North American desert southwest, in eastern Africa, and in southern China (Supplementary Fig.

127 1b). Areas with the lowest values of observed GDM and GDE were mostly distributed in

128 northern North America and Europe (Supplementary Fig. 1d).

129 Insect genetic diversity correlates with latitude

While latitude did not significantly explain GDM or GDE across the entire planet (Table

131 1), it was correlated with GDE after removing cells above 60 latitude, which includes areas 
132 covered by glaciers and tundra during the last glacial maximum (LGM; median slope quadratic $=$

1330.002 [95\% highest density interval (HDI): 0.001, 0.003], median $\mathrm{R}^{2}=0.103$ [95\% HDI: 0.022 ,

$1340.221])$. In contrast to latitudinal diversity gradients for species richness in most taxa, insect

135 GDE increased towards the poles (up to 60 latitude) and decreased towards the equator (Fig.

136 3). The same pattern is seen in GDM, although the pattern does not exhibit a strong statistical

137 trend, where the $95 \% \mathrm{HDI}$ of the predictor overlapped zero (slope quadratic $=2 \mathrm{e}-4[-5 \mathrm{e}-5,4 \mathrm{e}-4]$,

138 Fig. 3).

\section{environment}

Higher GDE values were mainly found in areas that rarely freeze. We divided the globe into areas above or below the global freeze-line (long-term minimum temperature of the coldest month (MTCM) above versus below $0^{\circ} \mathrm{C}$ ) and found that GDE is significantly higher above this

144 line than below it (Welch's unequal variance $t$-test; mean $\mathrm{GDE}_{\text {above }}-$ mean $\mathrm{GDE}_{\text {below }}=0.042 ; \mathrm{t}=$ $-5.804, \mathrm{df}=184.690, P<0.001)$, while GDM showed no significant correlative trend against this binary metric $(P=0.525)$.

We explored relationships among GDM, GDE, and environmental predictors within each

148 cell using Bayesian generalized linear mixed models (GLMMs). Predictors included bioclimatic

149 variables describing current climate, variables summarizing climate variation since the LGM

150 ("historical climate"), a spatial habitat variation metric, a human habitat modification metric, and

151 topographic variables. We found that GDM and GDE covary significantly with current climate

152 and that both reach high values in the hottest regions of the planet. Notably, predictors

153 describing human habitat modification, spatial habitat variation, and topography did not

154 significantly predict either GD metric. After reducing the set of potential predictors to three 155 current and historical climate variables for GDM (Supplementary Table 1) and six current and 
historical climate variables for GDE (Supplementary Table 2), we were able to compare three hypotheses: $\mathrm{H} 1$ ) current climate; $\mathrm{H} 2$ ) historical climate; and H3) current + historical climate best explain the two GD metrics. We constructed models for these hypotheses using a Bayesian GLMM approach that accounts for spatial autocorrelation (SAC; see Methods) ${ }^{73}$. The most parsimonious models were selected based on an approximate leave-one-out cross-validation procedure (LOO; see Methods) that uses the expected log predictive density (ELPD; analogous to information criteria, i.e., Akaike's Information Criterion) as the utility function. Using this

163 criterion, the best model for both GDM and GDE gave support to $\mathrm{H} 1$ : current climate. The $\mathrm{H} 1$

164 models for GDM and GDE included the maximum temperature of the warmest month variable

165 (MTWM). The best fit model (H1) for GDM additionally included precipitation seasonality, while

166 the best fit model $(\mathrm{H} 1)$ for GDE additionally included temperature seasonality and precipitation

167 of the wettest month (PWM) (Fig. 4, Table 2).

171 positively with GDM (slope $=0.002$ [0.001, 0.003]; Fig. 4), and precipitation seasonality trends negatively (slope $=-0.001[-0.002,-1 e-4]$; Fig. 4).

174 HDI: 0.152, 0.483]). MTWM was the only variable with a significant trend (Fig. 4). MTWM (slope $175=0.014[0.004,0.025])$ and temperature seasonality (slope $=0.008[-0.004,0.020])$ both trend 176 positively with GDE, whereas PWM trends negatively with GDE $(-0.004[-0.016,0.008])$. Over $23 \%$ and $32 \%$ of the global observed variation in GDM and GDE, respectively, can

178 be explained by current climate $(\mathrm{H} 1)$. There was no residual spatial autocorrelation in the final 179 models (Table 2). In addition, all parameter posterior distributions had less than 12\% overlap 180 with their prior distributions, indicating high identifiability (Supplementary Fig. 3). 


\section{Global predictions of insect genetic diversity}

We then used the best-fit model $(\mathrm{H} 1)$ to predict and map the global distribution of GDM and GDE individually and jointly at the original spatial scale used for modeling (193 km x 193 $\mathrm{km}$ resolution) across the globe, including unsampled areas (Fig. 2, Supplementary Fig. 4). We omitted predictions in all areas exposed to environmental conditions that fell outside the model training range, including Antarctica, a large portion of northern Africa, the Arabian Peninsula, parts of central Asia, and interior Greenland (Fig. 2; shown in gray; Supplementary Fig. 5).

Areas predicted to have high levels of both average genetic diversity and evenness (GDM and GDE; above the 90th percentile) include southeastern North America and southern India, while the regions with the very highest predicted values include southern and southwestern Australia, parts of the desert southwest of North America, and southern India

192 (Supplementary Fig. 1a; Fig. 2). Areas predicted to have the lowest GDM and GDE values 193 (below the 10th percentile for both) were found in Patagonia and the northern Nearctic and 194 Palearctic (Supplementary Fig. 1c). When considered independently, GDM is predicted to be highest (above the 90th percentile) in the temperate forest regions of eastern North America

196 (Supplementary Fig. 1e; Fig. 2), yet is predicted to be generally low for much of the Neotropics

197 (Fig. 2). The very lowest GDM areas (below the 10th percentile) are distributed across the nearctic and palearctic tundra, the entire Andes mountains chain, and areas in the Himalayan mountains (Supplementary Fig. 1g). When GDE is considered independently, it is predicted to be the highest (above the 90th percentile) throughout Australia, the southeast and desert southwest of North America, as well as much of the Indian subcontinent and the outer fringes of

202 Saharan Africa (Supplementary Fig. 1i). On the other hand, GDE is predicted to be lowest

203 (below the 10th percentile) in northern Europe and parts of the nearctic and palearctic tundra as 204 well as southern Patagonia in South America (Supplementary Fig. 1k; Fig. 2). 


\section{Taxon-specific patterns of GD}

Six insect orders contain $97.2 \%$ of all OTUs in this study (Supplementary Fig. 6;

207 Supplementary Table 3). In order of prevalence, they include Diptera, Lepidoptera,

208 Hymenoptera, Coleoptera (the four mega-diverse orders that include ca. $80 \%$ of known insect

209 species), Hemiptera, and Trichoptera. The remaining $2.8 \%$ of OTUs belong to 20 additional

210 insect orders.

211 To investigate the influence of the three most prevalent orders (Diptera, Lepidoptera,

212 and Hymenoptera, $84.4 \%$ of total) we removed these orders from the full dataset and

213 reanalyzed patterns of GDE and GDM. Using Welch's unequal variance t-tests, we found no

214 difference in GDE estimates between the full and reduced datasets (Supplementary Fig. 7; $P=$

215 0.335). However, GDM was slightly but significantly lower in the full dataset $\left(\right.$ mean $_{\text {diff }}=-0.003$,

$216 \mathrm{df}=91.195, P=0.002)$.

217 OTU sampling across the most abundant three orders varied geographically

218 (Supplementary Fig. 8). We calculated OTU sampling as the number of OTUs per order within

219 each cell. Diptera dominated OTU sampling towards the poles, while Lepidoptera dominated

220 sampling towards the tropics and in some temperate locations, and Hymenoptera typically

221 accounted for fewer than $50 \%$ of OTUs sampled, with overrepresented sampling in Madagascar

222 (Supplementary Fig. 8).

\section{Discussion}

We found clear, and in some cases surprising, global biogeographic patterns of insect

226 genetic diversity (Fig. 2; Supplementary Fig. 1). There is a reversed latitudinal gradient for GDM

227 and GDE, with both significantly lower in the tropics than in temperate and subtropical regions 
on either side of the equator. GDM and GDE have bimodal distributions which peak in areas that were unglaciated during the last glacial maximum $\left(\mathrm{LGM},<60^{\circ}\right.$ latitude, $18-21,000$ years ago, ${ }^{74}$ and are generally lower in the wet tropics and in temperate areas that were glaciated or tundra-like during the LGM (>60 latitude). This suggests that the forces underlying intraspecific genetic diversity are inherently different from those driving the classical negative latitudinal gradients in species richness and phylogenetic diversity found in major arthropod groups such

234 as ants and spiders ${ }^{75-77}$, as well as plants ${ }^{78}$, which are expected to be strongly linked to insect

235 biogeographic patterns. Bees (order Hymenoptera) are one notable exception, showing a

236 bimodal latitudinal gradient similar to what we find, with highest richness at mid-latitudes ${ }^{79}$.

237 While neutral theories of biodiversity predict positive species genetic diversity correlations

238 (SGDC) ${ }^{31,80,81}$, there are also conditions for which one would expect weak or even negative

239 correlations, e.g. neutral conditions paired with high mutation rates ${ }^{82}$ or greater niche breadths

240 result in higher genetic diversity, but fewer species in a community ${ }^{83}$. However, many

241 confounding factors will affect how species diversity metrics relate to GDM and GDE, and these

242 factors may have both positive and negative effects, leading to large variation in the sign and

243 intensity of SGDCs ${ }^{84}$, especially at a global scale in such a broad taxonomic group such as

244 insects.

The bimodal latitudinal gradient we find also contrasts with recent macrogenetic studies

246 of vertebrates, all of which find a negative latitudinal gradient of genetic diversity with average

247 values peaking in the tropics and declining poleward, including mammals ${ }^{20}$, amphibians ${ }^{22}$, and

248 fishes ${ }^{21}$. Our finding of lower genetic diversity in areas that were glaciated or tundra during the

249 LGM is consistent with a gradient of lower haplotype richness in recently unglaciated areas

250 found in European butterflies ${ }^{30}$ based on the same COI data from BOLD used here. Similarly,

251 aquatic insect species have lower intraspecific genetic diversities in recently unglaciated areas

252 of Europe compared to Neotropical areas ${ }^{32}$. 
Why would GDM and GDE be lower in areas like the wet tropics when the species diversities of most insect groups reach their peaks in these habitats ${ }^{87,88}$ ? Rapoport's Rule, the tendency for species' range sizes to increase with increasing latitude ${ }^{69,70}$, might explain this

256 result because species with larger ranges tend to harbor greater genetic diversity ${ }^{65,89}$.

257 Macrogenetic studies tend to calculate intraspecific genetic diversity at the grid-cell level, and 258 extratropical cells are likely dominated by species with large ranges, while tropical cells are 259 likely dominated by species with smaller ranges. Thus, coalescent times among sampled alleles 260 within each species in each extratropical cell will tend to be older, yielding larger average 261 pairwise distances, the metric we use for $\mathrm{GD}^{90}$.

262 A few additional mechanisms may play a role in explaining higher insect extratropical

263 GDM. Wide-ranging extratropical species can usually tolerate a broader range of climatic 264 variation, whereas limited-range tropical species tend to have a narrow climatic niche, stronger 265 habitat specializations, and narrower physiological tolerances $\left({ }^{91}\right)$. While peaks of GDM and 266 GDE may be driven by larger range sizes and greater physiological tolerances of species in hot, 267 seasonal areas, other studies have found that larger range sizes in temperate species can lead 268 to greater population genetic structure ${ }^{27}$. This could in turn lead to lower levels of local GDM if 269 the spatial resolution of sampling, i.e., grid size, is smaller than the population range sizes of 270 locally occurring species ${ }^{92}$. However, the coarse resolution of the cells we use $\left(37,249 \mathrm{~km}^{2}\right)$ 271 likely avoids this issue.

It is also possible that insect GDM and GDE patterns reflect their unique life history traits

273 and responses to short-term environmental shifts. For instance, observed and predicted

274 patterns of GDM and GDE (Fig. 2) are higher in areas where insect diapause, the temporary

275 suspension of development during the life cycle, is more prevalent $\left({ }^{91}\right)$. Insect diapause is

276 thought to provide adaptive tolerance to wider abiotic conditions and may result in larger and

277 more uniform ranges ${ }^{91,93}$. Given the positive relationship between range size and GD ${ }^{65,89}$, this 278 provides a possible mechanistic relationship that connects Rapoport's Rule and the higher and 
279 more uniform genetic diversities found in higher latitude regions with pronounced seasonality.

280 Another important feature of GDE is that it is lower in areas that experience frequent freezing,

281 i.e., below the freeze-line, which may be related to the range of temperatures encountered by a

282 species. Although this might seem counterintuitive, insect species that enter diapause in

283 habitats that seasonally accumulate substantial snow are likely to encounter less extreme

284 temperatures than those in more exposed habitats of temperate deserts, where large

285 temperature oscillations are common ${ }^{94}$. In this light, we might predict more uniform and higher

286 levels of GD in Australia, which both is above the freeze-line and has high temperature

287 seasonality with little snow accumulation.

288 Since species diversity patterns of specialist insect herbivores correlate with their host

289 plants' ${ }^{95}$, some of the environmental correlates associated with high GDM and GDE in insects

290 may be more directly tied to the climatic determinants underlying global plant diversity patterns

29196,97 . Nearly half of all insect species are herbivorous, yet this varies across orders ranging from

$292 \sim 99 \%$ of Lepidoptera, 30-35\% of Diptera and Coleoptera, yet only 10-15\% of Hymenoptera ${ }^{98}$.

293 Insects and angiosperms have species richness patterns with similar poleward gradients ${ }^{78,99}$

294 and likely evolved in the tropics with subsequent adaptations for wider environmental tolerances

295 associated with temperate radiations ${ }^{100}$. Although the diversities of insects and plants are tightly

296 correlated ${ }^{101}$, we found no significant correlations between habitat heterogeneity, a derived

297 measure of variability in remotely sensed metrics of vegetation diversity, and GDM or GDE,

298 suggesting that specific aspects of plant community composition, rather than just plant species

299 richness, affects insect genetic diversity. Further, host plant intraspecific genetic diversity

300 demonstrably influences herbivorous insect community assembly ${ }^{102,103}$. A potentially fruitful

301 area of future investigation would be to search for links between the genetic diversity of local

302 insect and plant assemblages.

303 While Rapoport's Rule may explain increasing extratropical genetic diversity, the

304 observed bimodal latitudinal gradient emerges as genetic diversity begins to decline poleward in 
305 the temperate regions. We hypothesize that the poleward spatial range expansions after the

306 LGM resulted in founder effects that led to the low levels of genetic diversity we detect in these

307 regions. This is consistent with many studies showing lower intraspecific genetic diversity in

308 organisms inhabiting regions that were previously tundra, cold steppes, or glaciated ${ }^{104}$,

309 presumably due to post-glacial expansions ${ }^{71}$.

310 The regions predicted to have high GDE and GDM correspond with known hotspots of

311 insect biodiversity. For instance, North American southwestern deserts have the highest

312 butterfly phylogenetic endemism in North America ${ }^{79,105}$. Southwestern Australian deserts also

313 have exceptionally high arthropod endemism ${ }^{106}$, and are among the original biodiversity

314 hotspots identified by ${ }^{107}$. The high GDM observed in eastern North America also corresponds

315 with high Odonata species diversity ${ }^{108}$.

316 The bimodal latitudinal gradient in GDE is likely influenced by mechanisms at least

317 partially independent of those that generate the same gradient in GDM. Higher levels of GDE,

318 reflecting lower variability among genetic diversities, could partially result from histories of

319 neutral community assembly processes ${ }^{61}$. Overcast et al. (2020) found in both simulated

320 communities and empirical arthropod, annelid, and tree datasets that ecologically neutral

321 communities tend to have higher GDE than non-neutral, i.e., niche-structured communities.

322 Here, the lower GDE in communities assembled via environmental filtering is likely caused by

323 increased genetic diversity in species with stronger local ecological adaptation. While this

324 suggests that equatorial insect communities may have stronger local niche-structured

325 mechanisms than temperate insect communities, consistent with the idea of stronger niche

326 conservatism in the tropics ${ }^{109}$, this is one of many hypotheses emerging from our study.

$327 \quad$ While GDM and GDE can be informative about processes underlying biodiversity

328 patterns, interpretation of GDM and GDE in isolation (or even together) without additional

329 information about the study system can lead to erroneous conclusions. For example, if the rare

330 and the least genetically diverse species go locally extinct, this could raise GDM for the 
331 remaining species. Similarly, a disturbed community with high GDE may be composed of

332 populations with low but similar genetic diversity, such that without also measuring GDM, the

333 low genetic diversity of the community may go unnoticed. Conversely, relatively high GDM in a

334 community may be driven by a few hyper-dominant taxa with high GD while a remaining

335 majority of low GD taxa. Alternatively, this same scenario of high GDM and low GDE could be

336 found in areas that have a mix of wide-ranging endemic taxa and several invasive species with

337 low genetic diversity ${ }^{110,111}$. Low GDE may highlight this driver when considered in context with a

338 priori hypotheses derived from other evidence. We recommend future macrogenetic studies at

339 regional scales to include metrics of the average and shape of GD distributions in addition to

340 ancillary information to effectively summarize and interpret the genetic diversity of assemblages.

341 Genetic diversity is critical to the survival of both the insects themselves, and the

342 complex networks of interactions to which many insects belong. High genetic diversity may

343 facilitate adaptation to changing climates and emerging diseases, two (of many) potential

344 drivers of the "insect apocalypse" ${ }^{44}$. In addition, genetic diversity contributes to the diversity and

345 stability of species interaction networks by affecting niche space and competition ${ }^{112}$, community

346 structure ${ }^{113}$, and network complexity ${ }^{114}$. At larger ecological scales, insect genetic diversity may

347 reflect ecosystem function and structure as reliably as other traditional macroecological metrics

348 such as species richness ${ }^{115}$. It can augment the resilience of ecosystems that provide

349 continuing services for humankind ${ }^{14}$, such as disease management, curbing the spread of

350 invasive plants, aiding sustainable agriculture, pollinating food crops, and controlling pests ${ }^{13}$.

351 While the metric of global human modification we considered did not significantly correlate with

352 GDM or GDE, there are many facets of anthropogenic disturbance acting at different spatial

353 scales that are difficult to summarize in a single metric ${ }^{116}$. The spatiotemporal resolution of

354 genetic sampling currently available does not permit rigorous assessment of how humanity

355 affects insect GD at a global scale, but a concerted increase in sampling effort, especially in the

356 data-poor regions we identify, will likely make this feasible in the not-to-distant future. 
By modeling relationships between environmental data and our two complementary measures of intraspecific genetic diversity, GDE and GDM, we also make predictions about assemblage-level genetic diversity in data-poor regions of the planet. This has the potential to fill a knowledge gap that far exceeds the undersampling and taxonomic uncertainties underlying

361 vertebrate and plant macroecological studies ${ }^{117,118}$. We provide targets for future efforts that will

362 fulfill global commitments to monitor and conserve genetic diversity, a biodiversity component

363 that has rarely been assessed or used to guide conservation decisions ${ }^{15}$, while focusing

364 attention on a data deficient group with evidence of global population declines ${ }^{119}$. While there

365 have been recent arguments that the value of putatively neutral intraspecific genetic diversity is

366 overstated in the context of conservation ${ }^{120}$, a large body of literature indicates otherwise ${ }^{121}$,

367 especially if neutral genetic diversity correlates with adaptive potential ${ }^{122,123}$. Taken together,

368 GDM and GDE are fundamental biodiversity metrics for documenting and understanding how

369 "the little things that run the world" can change, persist, and potentially adapt in the face of

370 global change ${ }^{124}$.

We downloaded cytochrome c oxidase $1(\mathrm{CO})$ mitochondrial sequence data for insects

378 directly from the BOLD webpage using the application programming interface (API)

379 (http://www.boldsystems.org/index.php/resources/api; downloaded 19 Nov 2019). Our initial 
database comprised 3,301,025 complete insect records before applying a series of quality filters. We used the BOLD database's OTU assignments (termed barcode identification numbers; BINs), which cluster similar sequences algorithmically and map them against the BOLD database ${ }^{125}$. After trimming end gaps from sequences, we removed exceptionally long sequences ( $>800$ base pairs, bp) which contained a large proportion of gaps that negatively impacted alignments and the calculation of summary statistics. In addition, we removed shorter sequences ( $<400 \mathrm{bp})$ that the BOLD database uses for BIN identification, but which may downwardly bias GD estimates. We also only used COI sequences when georeferenced metadata with geographic coordinates were available. Sequence alignments were independently performed for each OTU within single sampled geographic raster cells, i.e., grid cells. We used default settings in Clustal Omega (v1.2.3) to align the sequences and visually assessed a subset of alignments to check for alignment errors ${ }^{126}$.

To reduce the potential impact of invasive species on our analyses, we removed transcontinental invasive species from the dataset using a list of invasive insect species compiled from seven resources: Global Insect Species Database, [http://www.issg.org/database; accessed 23 May, 2020]; Invasive Species Compendium [https://www.cabi.org/isc/; accessed 24 May, 2020]; Center for Invasive Species and Ecosystem Health [https://www.invasive.org/; 397 accessed 24 May, 2020]; Invasive Alien species in South-Southeast Asia ${ }^{127}$; Japan Ministry of 398 the Environment [https://www.env.go.jp/en/nature/as.html; accessed 24 May, 2020]; European 399 Alien Species Information Network [https://easin.jrc.ec.europa.eu/easin/Home; accessed 24 400 May, 2020]. We identified all species and OTUs present on multiple continents and removed 401 those on the invasive species list from our dataset. While some invasive species may be 402 restricted to single continents, removal of such taxa was not possible given the lack of 403 information on changes in insect range boundaries and species assignments. 


\section{Calculating the evenness and mean of genetic diversity (GDE and}

405 GDM)

Global macrogenetic studies have so far focused on spatially defined metrics that

407 summarize the genetic diversities calculated across all species sampled from an area of

408 arbitrary spatial resolution ${ }^{19,128}$. This is most commonly the average genetic diversity or,

409 alternatively, a measure of the allelic richness derived from the total number of unique and/or

410 common alleles of a genetic locus across all taxa within an area ${ }^{129}$. We used two distinct

411 summaries of genetic diversity - the mean genetic diversity (GDM) and the evenness of this GD

412 per unit of area (GDE). To obtain the GD for each OTU per grid cell, we calculated nucleotide

413 diversity as the average number of nucleotide differences across all pairwise sequence

414 comparisons per OTU per base pair ${ }^{90,130}$. Aggregated across OTUs within each grid cell, GDM

415 is then defined as the average GD among OTUs in each grid cell, following ${ }^{20}$. Because the

416 distribution of GDM at the grid cell scale was highly skewed towards zero, we performed a

417 square-root transformation to achieve a more normal distribution. All subsequent statistical

418 analyses of GDM at the grid cell scale were based on the transformed GDM.

419 While GDM is a standard metric in the macrogenetic toolbox, GDE is derived from a set

420 of metrics known as Hill numbers that permit direct comparisons of diversity across scales and

421 data types ${ }^{131-133}$. GDE is then defined as the first-order Hill number of GD across OTUs per grid

422 cell, corrected by sampled OTU richness ${ }^{61}$ :

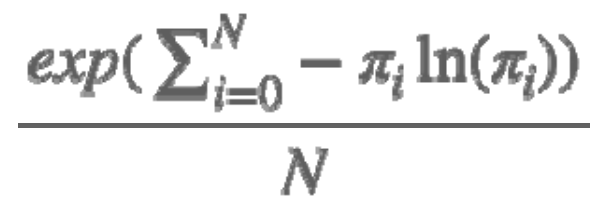

424 Where $N$ is the number of OTUs in the assemblage and $\square_{i}$ is the GD for a single OTU.

425 Correcting for sampled OTU richness allows for comparison across assemblages of different

426 numbers of OTUs. The numerator of this metric is the exponential of Shannon's diversity index, 
427 which is also referred to as Shannon's information measure or Shannon's entropy in the

428 literature ${ }^{134}$. It is commonly used to describe evenness and variability of species abundances

$429{ }^{135,136}$, and here we adapt it to do the same for genetic diversities calculated from all species

430 sampled from a particular area.

431 A higher GDE indicates where most OTUs have a similar GD (Fig. 1), whereas a lower

432 GDE arises when GD values across the community diverge considerably ${ }^{135}$. Low GDE can take

433 a variety of shapes, but the most common shape for low GDE cells in our observed data is

434 markedly L-shaped (Fig. 1).

435 Spatial resolution and sampling decisions

To assess how the spatial scale and density of OTU sampling impacted our results and

437 to establish a sampling strategy that maximizes the amount of information, we calculated both

438 metrics at 1) three different spatial resolutions, and 2) three thresholds of minimum OTU sample

439 sizes per grid cell. The spatial resolutions include $96.5 \mathrm{~km} \times 96.5 \mathrm{~km}, 193 \mathrm{~km} \times 193 \mathrm{~km}$, and

$440 \quad 385.9$ km x 385.9 km equal-area grid cells using a Behrmann cylindrical equal-area projection,

441 which are $1^{\circ}, 2^{\circ}$, and $4^{\circ}$ longitude at $30^{\circ} \mathrm{N}$. At each of three spatial resolutions, we considered a

442 minimum of 100,150 , or 200 unique OTUs per grid cell, as these approach the lower bounds of

443 the sample size needed to effectively estimate the diversity of a community using Hill numbers

$444 \quad 137$. We then selected the spatial resolution and minimum number of OTUs per grid cell that

445 maximized the average number of OTUs per grid cell, the number of grid cells, and the average

446 number of taxonomic orders per grid cell, while minimizing variation in the number of OTUs

447 across grid cells. With respect to numbers of sampled allele copies per OTU, we used a

448 minimum of three individuals per OTU per grid cell. This is a conservative approach to estimate

449 GD while still maximizing data use given that many BOLD data submissions omit duplicate

450 alleles and that coalescent theory suggests that using average pairwise distance from 5-10 
samples per OTU provides estimates of genetic diversity that are as reliable as those obtained

452 from hundreds of samples ${ }^{90}$.

We found that a grid cell resolution of $193 \mathrm{~km} \times 193 \mathrm{~km}$ with a minimum of 150 OTUs

454 per grid cell minimized variation in the number of OTUs across grid cells, while maximizing the

455 number of grid cells, the average number of OTUs per grid cell, and the average number of

456 taxonomic orders per grid cell (Supplementary Fig. 9). This filtering criteria led to a final dataset

457 that included 2,362,636 COI sequences from 95,540 OTUs sampled across 187 globally

458 distributed grid cells. On average, each cell contained ten insect orders, 460 OTUs, and 4,013

459 individuals. We calculated variation in the number of OTUs per cell as the difference between

460 the upper and lower 90\% highest density interval (HDI) of OTUs across cells yielding a

461 difference of 1779 OTUs.

$462 \quad$ Because $97.2 \%$ of OTUs are represented by six taxonomic orders (Supplementary Fig.

463 6; Supplementary Table 3), with 85\% represented by three (Diptera, Lepidoptera, and

464 Hymenoptera), we investigated whether and to what degree over-represented orders might be

465 driving the signal of GDE and GDM. To examine whether any of these three most dominant

466 orders deviate from global patterns of genetic diversity, we compared the global frequency

467 distributions of per-cell GDM and GDE from these three orders combined with the distribution of

468 these summary statistics for the entire data set. The distributions of per-cell GDE and GDM

469 between these filtered data sets and the original data set were compared using Welch's unequal

470 variance t-tests ${ }^{138}$.

$471 \quad$ Although coalescent theory predicts that the number of allele copies per OTU per grid

472 cell will have a limited impact on the per OTU genetic diversity ${ }^{90}$, we examined whether this

473 assumption was met in the data by testing for Pearson's correlations between the per OTU GD

474 and number of individuals per OTU $(r=0.030, P<0.001)$. Similarly, to investigate whether per

475 grid cell sampling, i.e., total number of individuals, number of individuals per OTU, and number

476 of OTUs per cell, had an effect on GDE or GDM, we tested for Pearson's correlations between 
477 these quantities (all $P>0.40$, Supplementary Table 4). In addition, we assessed sampling

478 variation by taking the ten most sampled grid cells (2,748 to 13,300 OTUs per grid cell) and

479 obtaining sampling distributions of GDM and GDE for each by resampling with replacement 150

480 OTUs per sample ( $\mathrm{N}=1000$ resamples) and calculating the summary statistics for each

481 resample (Supplementary Fig. 10).

\section{Environmental variable selection}

483 We aggregated a total of 47 abiotic, biotic, and anthropogenic variables that potentially influence

484 intraspecific genetic diversity in insect communities (Supplementary Table 5). We removed

485 highly correlated variables $(r>0.75)$, prioritizing variables that represent climate extremes,

486 climate variability, habitat variability, last glacial maximum (LGM) climate stability, and human

487 influence on the environment.

$488 \quad$ We retained a final data set of 11 ecologically relevant variables: five bioclimatic

489 variables, habitat heterogeneity, global human modification, and four metrics of climate stability

490 (temperature and precipitation) since the LGM (Supplementary Table 5). The five bioclimatic

491 variables describe climate extremes and variability, and were obtained from the CHELSA

492 database ${ }^{139}$. They include maximum temperature of the warmest month (MTWM), minimum

493 temperature of the coldest month (MTCM), precipitation of the wettest month (PWM),

494 precipitation of the driest month (PDM), temperature seasonality, and precipitation seasonality

495139,140 . The habitat heterogeneity metric was calculated as the standard deviation of the

496 Enhanced Vegetation Index, which was derived from the Moderate Resolution Imaging

497 Spectroradiometer (MODIS) $\left(2.5\right.$ arc-min; $\left.{ }^{141}\right)$. The human modification variable is a cumulative

498 measure of human modification to terrestrial areas ${ }^{142}$. Measures of both the historical trend and

499 variability of temperature and precipitation over the last 21,000 years were obtained from ${ }^{20}$. The

500 specific definitions of these derived metrics include "deep-time climate trend", the change in 
501 climate within each century, averaged across centuries, and "deep-time climate variability",

502 meaning the standard deviation around the change in climate, averaged across centuries. Low

503 deep time trend values indicate regions with long-term climate stability, while low variability

504 values indicate regions with short-term climate stability. Each variable was aggregated from its

505 original resolution (see Supplementary Table 5) to $193 \mathrm{~km}$ by $193 \mathrm{~km}$ resolution bilinear

506 interpolation.

507 In addition, we explored the relationship between GDE and GDM and a binary variable

508 delineating the globe along the freeze-line. Here, areas with a MTCM above $0^{\circ} \mathrm{C}$ are considered

509 above the global freeze-line, while areas with a MTCM below $0^{\circ} \mathrm{C}$ are considered below this

510 line. These regions have been found to correspond with sharp community turnover in birds ${ }^{143}$

511 and could correlate with critical life processes for insects.

512 Modeling approach

513 To identify the models that best explain the global distribution of GDM and GDE in

514 insects, we applied multimodel inference using Bayesian approaches. We modeled a set of

515 variables underlying environment, latitude, and the global freeze-line on the GDM and GDE of

516 insect assemblages independently. The necessary complexity of the modeling procedure

517 outlined below precluded the construction of a model including the combined effects of all

518 variables.

We prioritized constructing a simple, interpretable linear model that predicts GDM and

520 GDE robustly across the globe by conducting model selection in two steps. First, we reduced

521 the number of potential predictor combinations from the set of 11 variables with low collinearity

522 using Bayesian regression coupled with projective prediction feature selection. This approach

523 minimizes the number of predictor variables in a simple model while retaining comparable

524 predictive power to a model that includes the full suite of predictors ${ }^{144} ;{ }^{145}$. For each model we 
525 used weakly informative priors on all slope parameters $(\mathrm{N}(0,0.1))$ and the error term $(\mathrm{N}(0,1))$.

526 We centered and scaled all predictors to standard deviation of 1 and mean of 0 prior to

527 modeling. We aimed to retain single candidate models of GDM and GDE.

528 If residual spatial autocorrelation (SAC) is present, the assumption of independent and

529 identically distributed residuals would be violated, resulting in potentially biased overprecision of

530 parameter estimates ${ }^{146}$. We tested for SAC in the residuals of the resulting simplified models

531 using Moran's I and 10,000 simulations implemented in the R package spdep v1.1-2 ${ }^{147}$. We

532 detected significant levels of SAC in the residuals of our GDE model (Moran's $I=0.149, P=$

5330.008 ) and our GDM model (Moran's $I=0.306, P<0.001)$.

534 Given this presence of SAC, we used a Bayesian generalized linear mixed-effects model

535 (GLMM) implemented in the R package glmmfields v 0.1 .4 to robustly model GDE and GDM

536 while accounting for SAC ${ }^{73}$. SAC is modeled as a random effect with a multivariate t-distribution

537 determining the shape of the covariance matrix. Model parameters were estimated from the

538 posterior distribution using a No U-Turn Sampler ${ }^{148,149}$. We again tested for SAC in the

539 residuals of these models using the same approach as above.

540 Since the covariance structure among predictors is modified by the spatial random

541 effects, we performed additional model selection with the simplified candidate models. The

542 simplified models allowed for the formulation of specific hypotheses on the relationship between

543 GD and the environment. We compared three hypotheses (see Results) using the approximate

544 LOO cross-validation procedure outlined above. After selecting a model, we used the

545 percentage of prior-posterior overlap to assess the identifiability of parameter estimates relative

546 to the information provided by their prior distributions ${ }^{150}$. Low overlap between the prior and

547 posterior distribution of a parameter indicates that there is sufficient information in the data to

548 overcome the influence of the prior.

549 We used a similar approach as above to test the effect of latitude on GDM and GDE. We 550 constructed Bayesian GLMMs with latitude as a linear predictor and a quadratic term for GDM 
551 and GDE. All priors were the same as those in the climate modeling procedure. We compared

552 the fit of the linear model, quadratic model, and an intercept model using approximate LOO

553 cross-validation. We used prior-posterior overlap to assess parameter identifiability.

554 We also independently tested the effect of the global freeze-line on GD using Welch's 555 unequal variance t-tests.

\section{Global genetic diversity map generation}

Using the final models of GDM and GDE, we created maps of the global distribution of

558 insect GD. We used 1000 draws from the posterior distribution to predict terrestrial

559 environments across the globe. We included all continents except Antarctica, which had no

560 observed data and included environments far more extreme than the observed data. We

561 created maps of the median predicted GDM, upper, lower, and range of the 95\% HDI, as well as

562 for GDE. In addition, we created bivariate color maps of these prediction intervals for combined

563 GDM/GDE to highlight areas where GDM and GDE vary in similar and different directions.

564 Multivariate environmental similarity surface (MESS) maps were created to visualize

565 how environmentally similar or different areas across the globe are compared to the model

566 training data ${ }^{151}$. These maps aid in identifying areas of high extrapolation and thus where

567 uncertainty for predictions is also high. Decreasing negative MESS values represent

568 increasingly non-analogous environments, and increasing positive values indicate increasing

569 similarity. We used the MESS results to mask areas with non-analogous environmental space

570 (values less than 0) on our global prediction maps, indicating areas with high prediction

571 uncertainty. 


\section{Data availability}

573 All geographic, environmental, and genetic data are available at dryad_link (will make

574 available upon acceptance).

575 Computer code

576 All code used for data processing and analysis is available at https://github.com/connor-

577 french/global-insect-macrogenetics. 


\section{Figure captions}

579 Fig. 1

580 Diagram illustrating genetic diversity mean (GDM) and genetic diversity evenness (GDE). A

581 local assemblage (c) is a set of operational taxonomic units (OTUs, analogous to species)

582 sampled from a single grid cell that are a subset of a wider regional pool, whose evolutionary

583 relationships are shown in (a). OTUs have varying amounts of genetic diversity (GD),

584 represented by green circles with sizes corresponding to magnitude of GD. Longer branches

585 among individuals within an OTU indicate a longer time to coalescence and therefore higher GD

586 (b). Panel (c) illustrates four local assemblages sampled from four different grid cells from the

587 same regional pool. The first local assemblage in (c) has high GDM and high GDE, represented

588 by OTUs with high and similar GD and a corresponding relatively flat curve on the rank plot in

589 (d). The second local assemblage in (c) has the same high GDM as the first assemblage in (c),

590 but has lower GDE, indicated by dissimilar circle sizes and a steeper curve in the corresponding

591 rank plot in (d). The third and fourth local assemblages in (c) have the same GDE as the first

592 and second assemblages respectively, but have lower GDM, indicated by the smaller circle

593 sizes and lower height curves on the rank plots in (d). This illustrates the complementary nature

594 of the two metrics, where GDM describes the average magnitude of GD in a local assemblage,

595 while GDE describes the distribution of GD in that same local assemblage. 
a) Regional phylogenetic tree

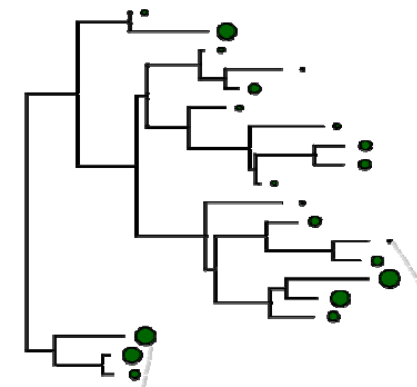

b) Genetic diversity (GD) of a single OTU

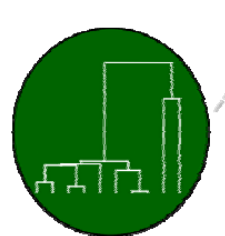

High GD

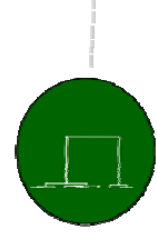

Low GD

c) Local assemblages with high/low GD mean (GDM) and GD evenness (GDE)

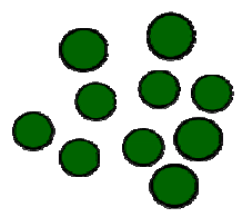

d) High GDM/High GDE

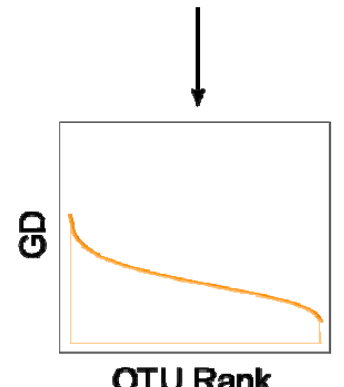

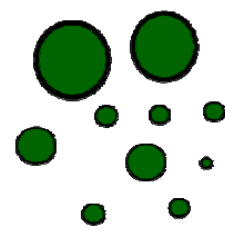

High GDM/Low GDE

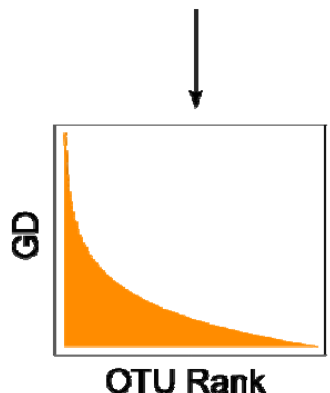

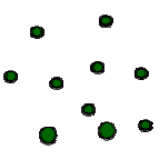

Low GDM/High GDE

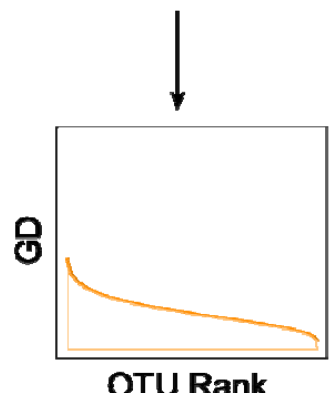

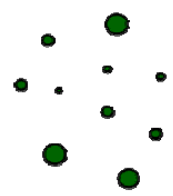

Low GDM/Low GDE

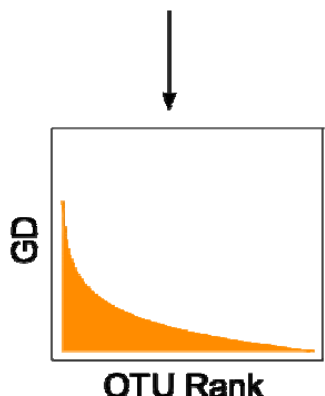


598 Fig. 2

599 The observed (a, c, e) and projected (b, d, e) distributions of GDM (a, b), GDE (c, d), and their

600 composite (E, F) across the globe. Values for the projected maps were derived from a Bayesian

601 GLMM model with environmental predictors. For GDM (b), the best fit model included MTWM

602 and precipitation seasonality, while for GDE (d), the best fit model included MTWM, temperature

603 seasonality, and PWM. The yellow lines drawn across the maps of GDE (c, d) indicate the

604 global freeze-line, where areas north of the line and inside the polygon in South America have

605 minimum temperatures that dip below $0^{\circ} \mathrm{C}$ (below the global freeze-line), and areas south of the

606 line and outside the polygon have minimum temperatures that remain above $0^{\circ} \mathrm{C}$ year-around

607 (above the global freeze-line). Areas above the freeze-line on average have higher GDE than

608 those below the global freeze-line. We masked in gray areas with environments non-analogous

609 to the environments used for modeling. MTWM = maximum temperature of the warmest month;

$610 \mathrm{PWM}=$ precipitation of the wettest month. 
bioRxiv preprint doi: https://doi.org/10.1101/2022 02 09.479762. this version posted February 10,2022 The copyright holder for this preprint (which was not certified by peer review) is the author/funder, who has granted bioRxiv a license to display the preprint in perpetuity. It is made available under aCC-BY-NC-ND 4.0 International license.

a)

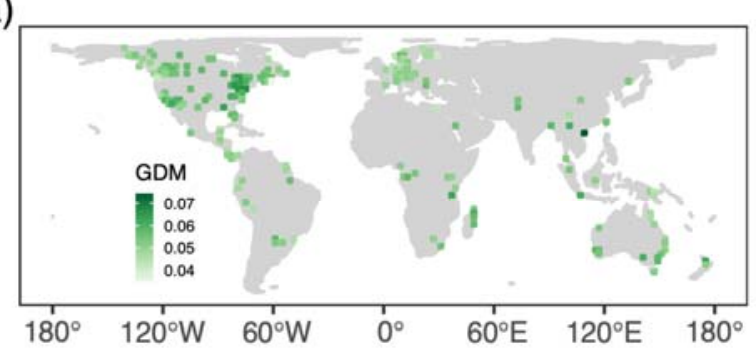

c)

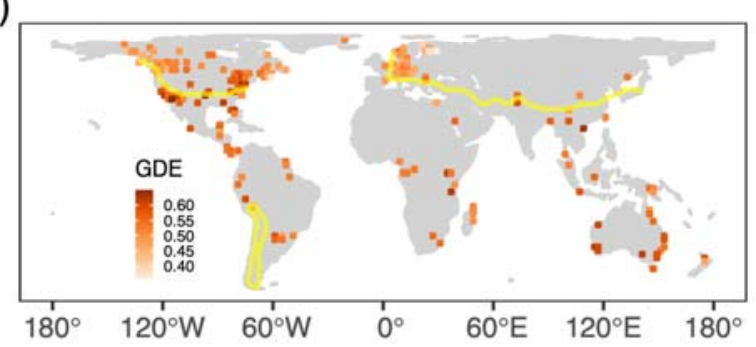

e)

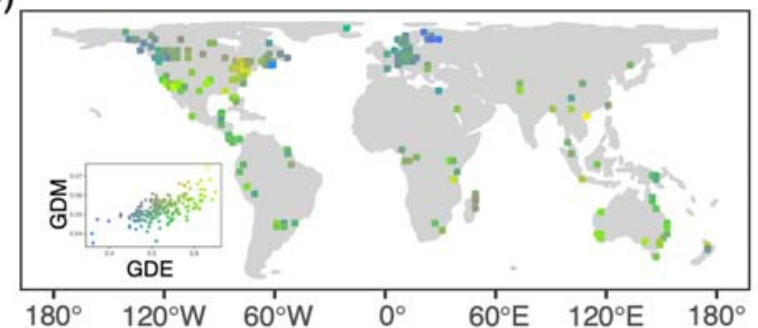

b)

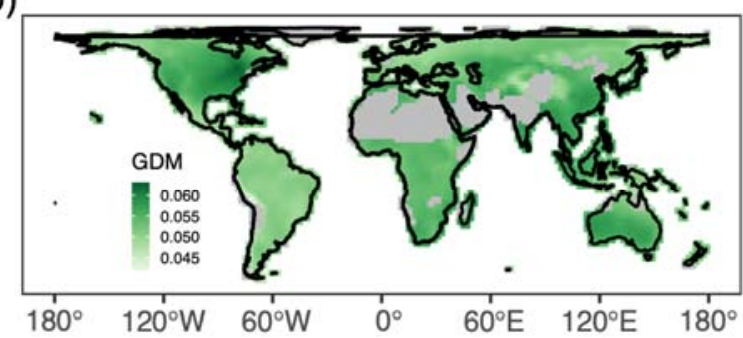

d)

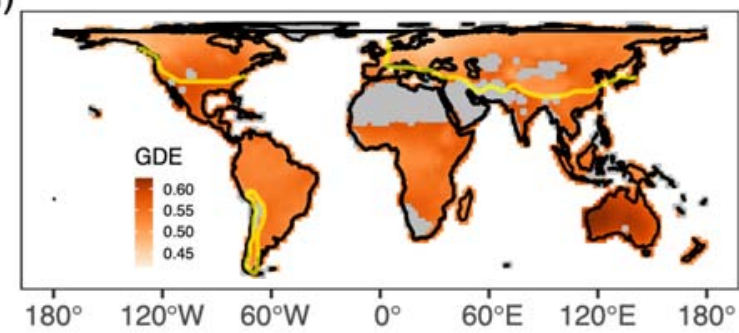

f)

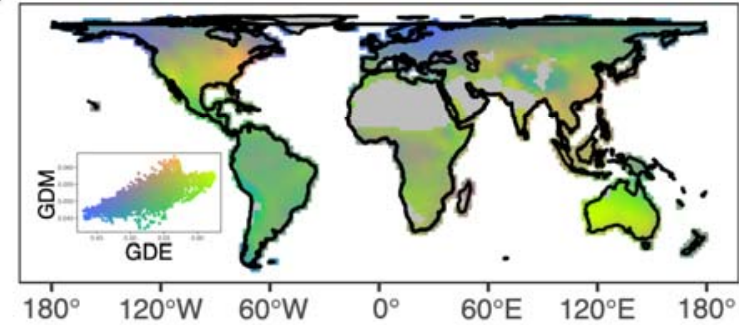


Fig. 3

613 GDM and GDE increase towards the poles until 60 latitude, the southernmost extent of

614 glaciated and tundra sites. When removing areas that were glaciated or tundra during the LGM

615 ( $N=100)$, GDE (c) showed a significant positive quadratic trend with latitude, while GDM

616 showed a qualitative positive quadratic trend (d) that was not statistically robust. The observed

617 data are plotted in dark green and orange, while the median, 70\% HDI, and 95\% HDI of

618 posterior predictions from Bayesian GLMM models are plotted in light green and orange. A

619 bimodal distribution of GDM (b) and GDE (d) is evident in the full observed data set $(N=187)$. A

620 Loess-smoothed trendline is overlaid to highlight this trend.

a)

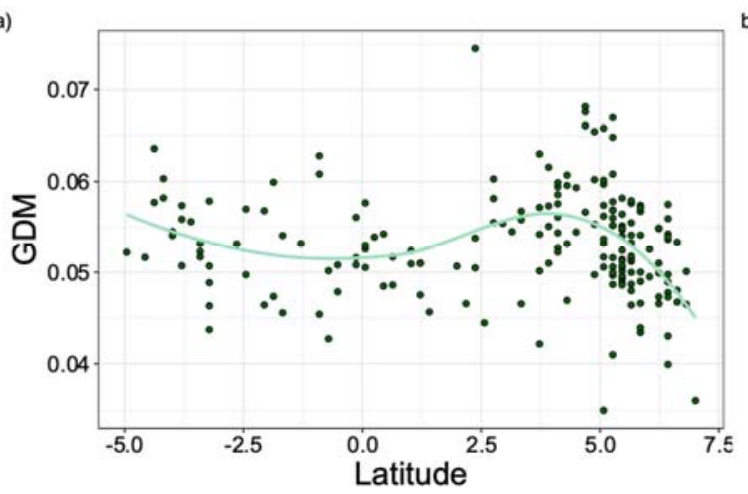

c)

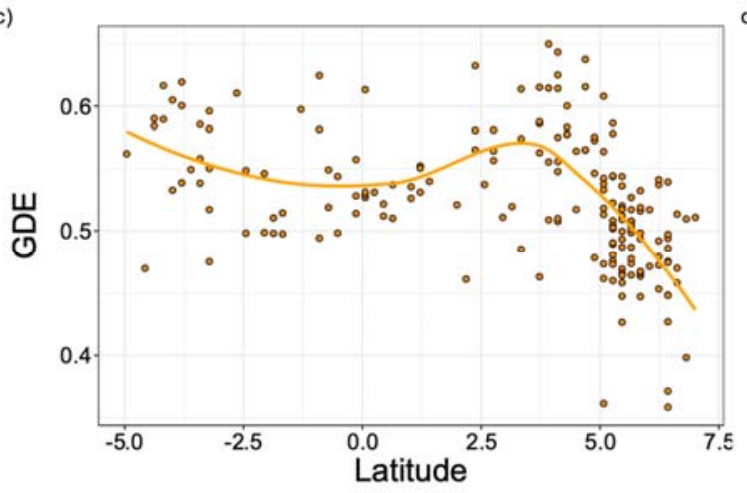

b)

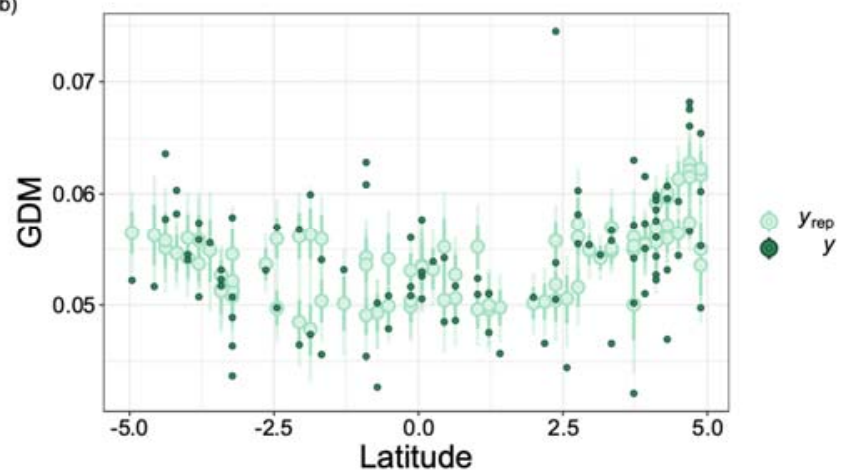

d)

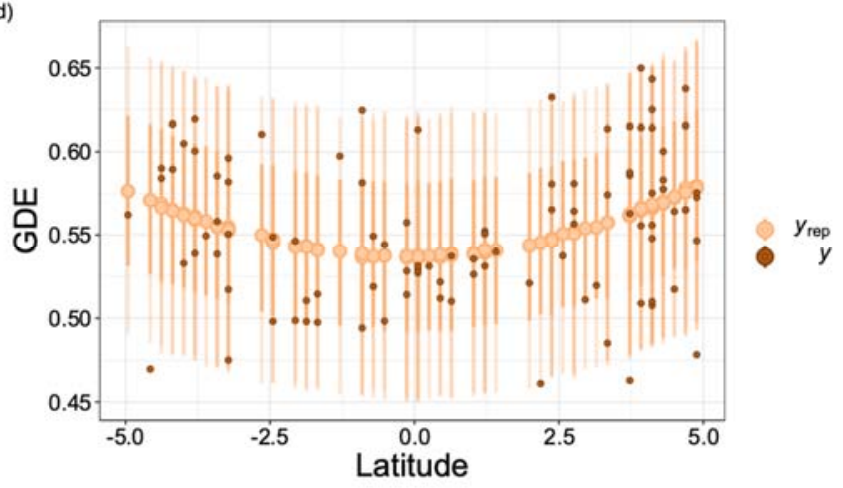


Fig. 4

623 Distributions of observed and predicted GDE and GDM. The gray lines in (a) and (c) are 1000

624 random samples from the posterior distribution of the GDM and GDE models. The green lines

625 are the observed distributions of GDM and GDE. The boxplot overlaid on (c) illustrates the

626 higher observed GDE above the global freeze-line (minimum temperature $>0^{\circ} \mathrm{C}$ ) versus GDE

627 below the global freeze-line (minimum temperature $<=0^{\circ}$ ). The observed differences in GDE

628 above and below the global freeze-line are reflected in the posterior draws, which we highlight

629 with two gray, dashed lines drawn through the medians of the observed data. The posterior

630 distributions of the slopes for each predictor are shown in (b) and (d). The thin bars under each

631 density plot indicate the $95 \% \mathrm{HDI}$ and the thick bars indicate the $70 \% \mathrm{HDI}$. MTWM = maximum

632 temperature of the warmest month; PWM = precipitation of the wettest month

a)

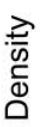

c)
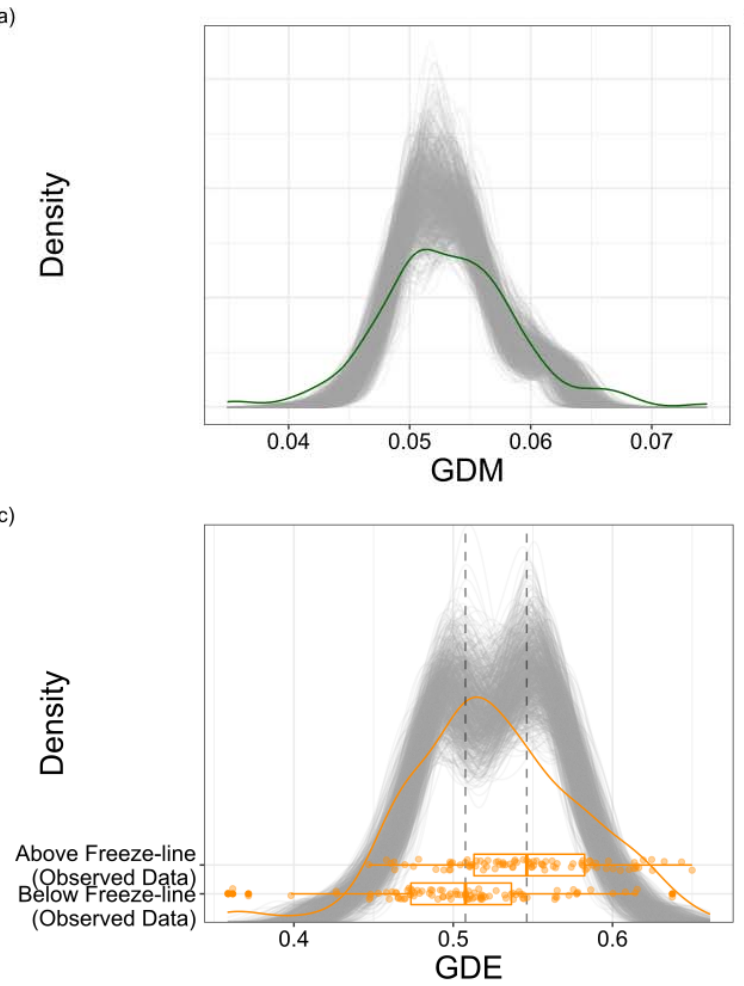

b)

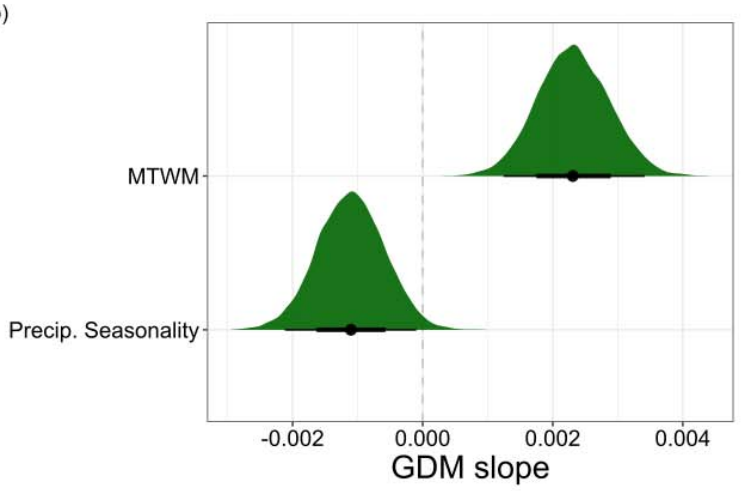

d)

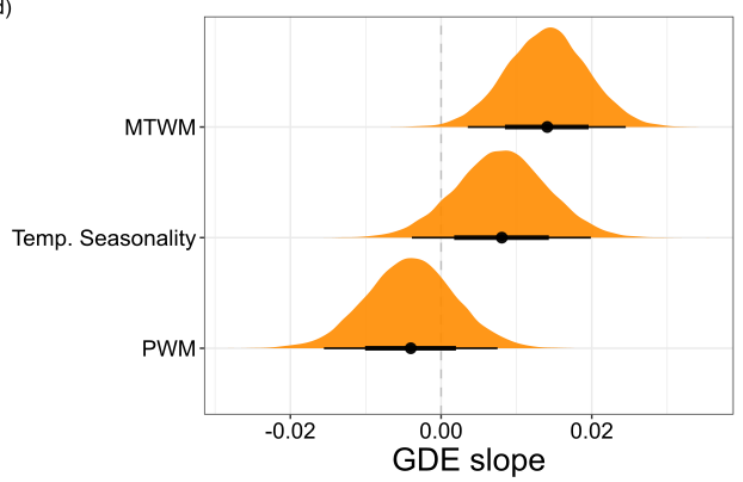




\section{Tables}

\section{Table 1}

636 Results for models of GDM, GDE, and latitude, either across the entire data set or only including

637 areas that were not glaciated or tundra during the LGM (indicated by model names with a

638 subscript 60).

\begin{tabular}{|c|c|c|c|c|c|c|c|}
\hline Model & Term & $\begin{array}{l}\text { Median } \\
\text { slope }\end{array}$ & $\begin{array}{l}\text { Lower 95\% } \\
\text { HDI }\end{array}$ & $\begin{array}{l}\text { Upper } \\
95 \% \text { HDI }\end{array}$ & $\begin{array}{l}\text { Median } \\
\mathbf{R}^{2}\end{array}$ & $\begin{array}{l}\text { Lower } \\
95 \% \mathrm{HDI}\end{array}$ & $\begin{array}{l}\text { Upper } \\
95 \% \text { HDI }\end{array}$ \\
\hline $\begin{array}{l}\text { GDM latitude + } \\
\text { latitude }\end{array}$ & linear & -0.001 & -0.002 & 0.0001 & 0.186 & 0.063 & 0.327 \\
\hline $\begin{array}{l}\text { GDM latitude + } \\
\text { latitude }^{2}\end{array}$ & quadratic & -0.0001 & -0.0002 & 0.0001 & 0.186 & 0.063 & 0.327 \\
\hline $\begin{array}{l}\text { GDE latitude + } \\
\text { latitude }^{2}\end{array}$ & linear & -0.006 & -0.013 & 0.001 & 0.261 & 0.102 & 0.417 \\
\hline $\begin{array}{l}\text { GDE latitude + } \\
\text { latitude }^{2}\end{array}$ & quadratic & -0.001 & -0.002 & 0.001 & 0.261 & 0.102 & 0.417 \\
\hline $\begin{array}{l}\mathrm{GDM}_{60} \sim \text { latitude + } \\
\text { latitude }^{2}\end{array}$ & linear & -0.0001 & -0.001 & 0.0007 & 0.231 & 0.083 & 0.382 \\
\hline $\begin{array}{l}\mathrm{GDM}_{60} \sim \text { latitude + } \\
\text { latitude }^{2}\end{array}$ & quadratic & 0.0002 & -0.0001 & -0.0004 & 0.231 & 0.083 & 0.382 \\
\hline $\begin{array}{l}\text { GDE }_{60} \sim \text { latitude + } \\
\text { latitude }^{2}\end{array}$ & linear & 0.0004 & -0.0024 & 0.0031 & 0.103 & 0.022 & 0.221 \\
\hline $\begin{array}{l}\text { GDE }_{60} \sim \text { latitude + } \\
\text { latitude }^{2}\end{array}$ & quadratic & 0.002 & 0.001 & 0.003 & 0.103 & 0.022 & 0.221 \\
\hline
\end{tabular}

640 The bolded model has at least one predictor with a 95\% highest density interval (HDI) that does

641 not overlap with zero, indicating a significant statistical association. 


\section{Table 2}

643 Results of the spatial linear modeling of environmental correlates for GDM and GDE.

\begin{tabular}{|c|c|c|c|c|c|c|c|c|c|c|}
\hline Model & Predictors & $\begin{array}{l}\text { Diff. in } \\
\text { ELPD }\end{array}$ & $\begin{array}{l}\text { SE in } \\
\text { diff. }\end{array}$ & ELPD & $\begin{array}{l}\text { SE } \\
\text { ELPD }\end{array}$ & $\begin{array}{l}\text { Median } \\
\mathbf{R}^{2}\end{array}$ & $\begin{array}{l}\text { Lower } \\
95 \% \mathrm{HDI}\end{array}$ & $\begin{array}{l}\text { Upper } \\
95 \% \text { HDI }\end{array}$ & Moran's I & $\begin{array}{l}P \text {-value } \\
\text { (Moran's }\end{array}$ \\
\hline GDM Current climate & $\begin{array}{l}\text { MTWM, precip. } \\
\text { seasonality }\end{array}$ & 0 & 0 & 746.215 & 16.704 & 0.234 & 0.088 & 0.385 & 0.040 & 0. \\
\hline $\begin{array}{l}\text { GDM Current climate } \\
+ \text { historical climate }\end{array}$ & $\begin{array}{l}\text { MTWM, precip. } \\
\text { seasonality, precip. } \\
\text { trend }\end{array}$ & -0.711 & 1.056 & 745.505 & 16.683 & 0.250 & 0.100 & 0.398 & 0.047 & 0. \\
\hline $\begin{array}{l}\text { GDM Historical } \\
\text { climate }\end{array}$ & Precip. trend & -7.149 & 5.368 & 739.066 & 16.646 & 0.202 & 0.072 & 0.342 & 0.045 & $0 . c^{\prime}$ \\
\hline GDE Current climate & $\begin{array}{l}\text { MTWM, PWM, } \\
\text { temp. seasonality }\end{array}$ & 0 & 0 & 346.465 & 11.935 & 0.327 & 0.152 & 0.483 & -0.018 & $0 . !$ \\
\hline $\begin{array}{l}\text { GDE Current climate } \\
+ \text { historical climate }\end{array}$ & $\begin{array}{l}\text { MTWM, PWM, } \\
\text { temp. seasonality, } \\
\text { temp. trend, temp. } \\
\text { variability, precip. } \\
\text { trend }\end{array}$ & -3.753 & 1.805 & 342.713 & 12.227 & 0.387 & 0.195 & 0.535 & 0.002 & $0 .\llcorner$ \\
\hline Historical climate & $\begin{array}{l}\text { Temp. trend, temp. } \\
\text { variability, precip. } \\
\text { trend }\end{array}$ & -5.099 & 4.359 & 341.366 & 12.076 & 0.291 & 0.119 & 0.454 & 0.018 & 0.6 \\
\hline
\end{tabular}

644

645 Each hypothesis we tested (current climate, historical climate, and current climate + historical

646 climate) had a unique set of predictors for GDM and GDE. Columns 3-6 contain summary

647 statistics (expected log predictive density, ELPD) from approximate leave-one-out cross-

648 validation model selection for spatial Bayesian GLMMs. The "diff. in ELPD" column indicates

649 differences in ELPD from the best fit model. In addition, columns 7-9 contain a summary of the

650 Bayesian $\mathrm{R}^{2}$ model fit statistic. Residual spatial autocorrelation for each model was calculated

651 using Moran's I and 10,000 simulations were used to calculate a $P$-value. HDI = highest density

652 interval; MTWM = maximum temperature of the warmest month; PWM = precipitation of the

653 wettest month. 


\section{References}

656 1. Jenkins, C. N., Pimm, S. L. \& Joppa, L. N. Global patterns of terrestrial vertebrate diversity

657 and conservation. Proc. Natl. Acad. Sci. U. S. A. 110, E2602-10 (2013).

658 2. Jarzyna, M. A., Quintero, I. \& Jetz, W. Global functional and phylogenetic structure of avian 659 assemblages across elevation and latitude. Ecol. Lett. 24, 196-207 (2021).

660 3. Faith, D. P. Conservation evaluation and phylogenetic diversity. Biol. Conserv. 61, 1-10 $661 \quad$ (1992).

662 4. Howard, C., Stephens, P. A., Pearce-Higgins, J. W., Gregory, R. D. \& Willis, S. G. The drivers of avian abundance: patterns in the relative importance of climate and land use. Glob. Ecol. Biogeogr. 24, 1249-1260 (2015).

5. Callaghan, C. T., Nakagawa, S. \& Cornwell, W. K. Global abundance estimates for 9,700 bird species. Proc. Natl. Acad. Sci. U. S. A. 118, (2021).

6. Cardoso, P., Pekár, S., Jocqué, R. \& Coddington, J. A. Global patterns of guild composition and functional diversity of spiders. PLoS One 6, e21710 (2011).

7. Safi, K. et al. Understanding global patterns of mammalian functional and phylogenetic diversity. Philos. Trans. R. Soc. Lond. B Biol. Sci. 366, 2536-2544 (2011).

8. Ratnasingham, S. \& Hebert, P. D. N. bold: The Barcode of Life Data System (http://www.barcodinglife.org). Mol. Ecol. Notes 7, 355-364 (2007).

9. Lawrence, E. R. et al. Geo-referenced population-specific microsatellite data across American continents, the MacroPopGen Database. Sci Data 6, 14 (2019).

675 10. Benson, D. A. et al. GenBank. Nucleic Acids Res. 41, D36-42 (2013).

676 11. Arribas, P., Andújar, C. \& Salces $\square$ Castellano, A. The limited spatial scale of dispersal in 677 soil arthropods revealed with whole $\square$ community haplotype $\square$ level metabarcoding. Molecular $678 \quad$ Ecology (2021). 
12. Macher, J.-N., Macher, T.-H. \& Leese, F. Combining NCBI and BOLD databases for OTU assignment in metabarcoding and metagenomic datasets: The BOLD NCBI_Merger. Metabarcoding and Metagenomics vol. 1 e22262 (2017).

13. Stange, M., Barrett, R. D. H. \& Hendry, A. P. The importance of genomic variation for biodiversity, ecosystems and people. Nat. Rev. Genet. 22, 89-105 (2021).

14. Des Roches, S., Pendleton, L. H., Shapiro, B. \& Palkovacs, E. P. Conserving intraspecific variation for nature's contributions to people. Nat Ecol Evol (2021) doi:10.1038/s41559-02101403-5.

15. Hoban, S. et al. Global commitments to conserving and monitoring genetic diversity are now necessary and feasible. Bioscience (2021) doi:10.1093/biosci/biab054.

16. Santini, L. et al. The interface between Macroecology and Conservation: existing links and untapped opportunities. Frontiers of Biogeography 13, e53025 (2021).

17. Schmidt, C. \& Garroway, C. J. The conservation utility of mitochondrial genetic diversity in macrogenetic research. Conserv. Genet. (2021) doi:10.1007/s10592-021-01333-6. Macrogenetics. Trends Genet. 33, 579-580 (2017).

19. Leigh, D. M. et al. Opportunities and challenges of macrogenetic studies. Nat. Rev. Genet. (2021) doi:10.1038/s41576-021-00394-0.

20. Theodoridis, S. et al. Evolutionary history and past climate change shape the distribution of genetic diversity in terrestrial mammals. Nat. Commun. 11, 2557 (2020). Commun. 11, 692 (2020).

22. Miraldo, A. et al. An Anthropocene map of genetic diversity. Science 353, 1532-1535 (2016).

23. Gratton, P. et al. Which Latitudinal Gradients for Genetic Diversity? Trends in ecology \& evolution 32, 724-726 (2017). 
705

706

707

708

709

710

711

712

713

714

715

716

717

718

719

720

721

722

723

724

725

726

727

728

729

730

24. Barrow, L. N., Masiero da Fonseca, E., Thompson, C. E. P. \& Carstens, B. C. Predicting amphibian intraspecific diversity with machine learning: Challenges and prospects for integrating traits, geography, and genetic data. Mol. Ecol. Resour. (2020) doi:10.1111/1755-0998.13303.

25. Millette, K. L. et al. No consistent effects of humans on animal genetic diversity worldwide. Ecol. Lett. 23, 55-67 (2020).

26. Theodoridis, S., Rahbek, C. \& Nogues $\square$ Bravo, D. Exposure of mammal genetic diversity to mid $\square 21$ st century global change. Ecography 44, 817-831 (2021).

27. Pelletier, T. A. \& Carstens, B. C. Geographical range size and latitude predict population genetic structure in a global survey. Biol. Lett. 14, 20170566 (2018).

28. Losey, J. E. \& Vaughan, M. The Economic Value of Ecological Services Provided by Insects. Bioscience 56, 311-323 (2006).

29. Valiente-Banuet, A. et al. Beyond species loss: the extinction of ecological interactions in a changing world. Funct. Ecol. 29, 299-307 (2015).

30. Dincă, V. et al. High resolution DNA barcode library for European butterflies reveals continental patterns of mitochondrial genetic diversity. Commun Biol 4, 315 (2021).

31. Papadopoulou, A. et al. Testing the Species-Genetic Diversity Correlation in the Aegean Archipelago: Toward a Haplotype-Based Macroecology? Am. Nat. 178, 241-255 (2011).

32. Salinas-Ivanenko, S. \& Múrria, C. Macroecological trend of increasing values of intraspecific genetic diversity and population structure from temperate to tropical streams. Glob. Ecol. Biogeogr. 30, 1685-1697 (2021).

33. Baselga, A. et al. Whole-community DNA barcoding reveals a spatio-temporal continuum of biodiversity at species and genetic levels. Nat. Commun. 4, 1892 (2013).

34. Wilson, R. J. \& Fox, R. Insect responses to global change offer signposts for biodiversity and conservation. Ecol. Entomol. 46, 699-717 (2021).

35. Wagner, D. L., Grames, E. M., Forister, M. L., Berenbaum, M. R. \& Stopak, D. Insect 
decline in the Anthropocene: Death by a thousand cuts. Proc. Natl. Acad. Sci. U. S. A. 118, e2023989118 (2021)

36. Gallien, L. \& Carboni, M. The community ecology of invasive species: where are we and what's next? Ecography 40, 335-352 (2017).

37. Smith-Ramesh, L. M., Moore, A. C. \& Schmitz, O. J. Global synthesis suggests that food web connectance correlates to invasion resistance. Glob. Chang. Biol. 23, 465-473 (2017).

38. Raven, P. H. \& Wagner, D. L. Agricultural intensification and climate change are rapidly decreasing insect biodiversity. Proc. Natl. Acad. Sci. U. S. A. 118, (2021).

39. Halsch, C. A. et al. Insects and recent climate change. Proc. Natl. Acad. Sci. U. S. A. 118, (2021).

40. Powney, G. D. et al. Widespread losses of pollinating insects in Britain. Nat. Commun. 10, 1018 (2019).

41. van Klink, R. et al. Meta-analysis reveals declines in terrestrial but increases in freshwater insect abundances. Science 368, 417-420 (2020).

42. Forister, M. L., Pelton, E. M. \& Black, S. H. Declines in insect abundance and diversity: We know enough to act now. Conservat Sci and Prac 1, e80 (2019).

747 43. Didham, R. K. et al. Interpreting insect declines: seven challenges and a way forward. Insect Conserv. Divers. 13, 103-114 (2020).

44. Montgomery, G. A. et al. Is the insect apocalypse upon us? How to find out. Biol. Conserv. 241, e108327 (2020).

45. Crossley, M. S. et al. No net insect abundance and diversity declines across US Long Term Ecological Research sites. Nat Ecol Evol 4, 1368-1376 (2020).

46. Fox, R. et al. Insect population trends and the IUCN Red List process. J. Insect Conserv. 23, 269-278 (2019). invertebrate conservation and how to overcome them. Biol. Conserv. 144, 2647-2655 
(2011).

48. Diniz-Filho, J. A. F., de Marco, P., Jr \& Hawkins, B. A. Defying the curse of ignorance: perspectives in insect macroecology and conservation biogeography. Insect Conserv. Divers. (2010) doi:10.1111/j.1752-4598.2010.00091.x.

49. Grames, E. M. et al. Trends in global insect abundance and biodiversity: A communitydriven systematic map protocol. OSF Registries (2019).

50. Wheeler, Q. D., Raven, P. H. \& Wilson, E. O. Taxonomy: Impediment or expedient? Science 303, 285 (2004).

51. Stribling, J. B., Pavlik, K. L., Holdsworth, S. M. \& Leppo, E. W. Data quality, performance, and uncertainty in taxonomic identification for biological assessments. J. North Am. Benthol. Soc. 27, 906-919 (2008).

52. Hebert, P. D. N. et al. Counting animal species with DNA barcodes: Canadian insects. Philos. Trans. R. Soc. Lond. B Biol. Sci. 371, 20150333 (2016).

53. Meier, R. et al. A re-analysis of the data in Sharkey et al.'s (2021) minimalist revision reveals that BINs do not deserve names, but BOLD Systems needs a stronger commitment

54. Hickerson, M. J., Meyer, C. \& Moritz, C. DNA-Barcoding will often fail to discover new animal species over broad parameter space. Syst. Biol. 55, 729-739 (2006).

55. Allio, R., Donega, S., Galtier, N. \& Nabholz, B. Large variation in the ratio of mitochondrial to nuclear mutation rate across animals: implications for genetic diversity and the use of mitochondrial DNA as a molecular marker. Mol. Biol. Evol. 34, 2762-2772 (2017).

56. Hudson, R. R. \& Turelli, M. Stochasticity overrules the 'three-times rule': genetic drift, genetic draft, and coalescence times for nuclear loci versus mitochondrial DNA. Evolution 57, 182-190 (2003).

57. Meiklejohn, C. D., Montooth, K. L. \& Rand, D. M. Positive and negative selection on the mitochondrial genome. Trends Genet. 23, 259-263 (2007). 
58. Hurst, G. D. D. \& Jiggins, F. M. Problems with mitochondrial DNA as a marker in population, phylogeographic and phylogenetic studies: the effects of inherited symbionts. Proc. Biol. Sci. 272, 1525-1534 (2005).

59. Deiner, K. et al. Environmental DNA metabarcoding: Transforming how we survey animal and plant communities. Mol. Ecol. 26, 5872-5895 (2017).

60. Sigsgaard, E. E. et al. Population-level inferences from environmental DNA-Current status and future perspectives. Evol. Appl. 13, 245-262 (2020).

61. Overcast, I. et al. A unified model of species abundance, genetic diversity, and functional diversity reveals the mechanisms structuring ecological communities. bioRxiv 2020.01.30.927236 (2020) doi:10.1101/2020.01.30.927236.

62. Wallace, A. R. \& Harvard University. Tropical nature, and other essays. (London, Macmillan and co., 1878).

63. Janzen, D. H. Why Mountain Passes are Higher in the Tropics. Am. Nat. 101, 233-249 (1967).

64. Moreau, C. S. \& Bell, C. D. Testing the museum versus cradle tropical biological diversity hypothesis: phylogeny, diversification, and ancestral biogeographic range evolution of the ants. Evolution 67, 2240-2257 (2013).

65. Buffalo, V. Quantifying the relationship between genetic diversity and population size suggests natural selection cannot explain Lewontin's Paradox. eLife 10, e67509 (2021).

66. Stebbins, G. L. Flowering Plants: Evolution above the Species Level. (Harvard University Press, 1974). doi:10.4159/harvard.9780674864856.

67. Gaston, K. J. \& Blackburn, T. M. The tropics as a museum of biological diversity: an analysis of the New World avifauna. Proceedings of the Royal Society of London. Series B: Biological Sciences 263, 63-68 (1996). species richness. Trends Ecol. Evol. 15, 311-315 (2000). 
69. Stevens, G. C. The Latitudinal Gradient in Geographical Range: How so Many Species Coexist in the Tropics. Am. Nat. 133, 240-256 (1989).

811 70. Ruggiero, A. \& Werenkraut, V. One-dimensional analyses of Rapoport's rule reviewed 812 through meta-analysis. Glob. Ecol. Biogeogr. 16, 401-414 (2007).

813 71. Hewitt, G. The genetic legacy of the Quaternary ice ages. Nature 405, 907-913 (2000).

814 72. Carnaval, A. C., Hickerson, M. J., Haddad, C. F. B., Rodrigues, M. T. \& Moritz, C. Stability 815 predicts genetic diversity in the Brazilian Atlantic forest hotspot. Science 323, 785-789 816 (2009).

817 73. Anderson, S. C. \& Ward, E. J. Black swans in space: modeling spatiotemporal processes 818 with extremes. Ecology 100, e02403 (2019).

819 74. Pielou, E. C. After The Ice Age. (The University of Chicago Press, 1991).

820 75. Dunn, R. R. et al. Climatic drivers of hemispheric asymmetry in global patterns of ant species richness. Ecol. Lett. 12, 324-333 (2009).

822 76. Economo, E. P., Narula, N., Friedman, N. R., Weiser, M. D. \& Guénard, B. Macroecology and macroevolution of the latitudinal diversity gradient in ants. Nat. Commun. 9, 1778 (2018).

77. Privet, K. \& Petillon, J. Differences in tropical vs. temperate diversity in arthropod predators provide insights into causes of latitudinal gradients of species diversity. bioRxiv 283499 (2018) doi:10.1101/283499.

78. Kreft, H. \& Jetz, W. Global patterns and determinants of vascular plant diversity. Proc. Natl. Acad. Sci. U. S. A. 104, 5925-5930 (2007).

79. Orr, M. C. et al. Global Patterns and Drivers of Bee Distribution. Curr. Biol. 31, 451-458.e4 (2021).

832 80. Vellend, M. Island biogeography of genes and species. Am. Nat. 162, 358-365 (2003).

833 81. Hubbell, S. P. The Unified Neutral Theory of Biodiversity and Biogeography. (Princeton $834 \quad$ University Press, 2001). doi:10.1515/9781400837526. 
835

836

837

838

839

840

841

842

843

844

845

846

847

848

849

850

851

852

853

854

855

856

857

858

859

860

82. Laroche, F., Jarne, P., Lamy, T., David, P. \& Massol, F. A neutral theory for interpreting correlations between species and genetic diversity in communities. Am. Nat. 185, 59-69 (2015).

83. Vellend, M. \& Geber, M. A. Connections between species diversity and genetic diversity. Ecol. Lett. 8, 767-781 (2005).

84. Lamy, T., Laroche, F., David, P., Massol, F. \& Jarne, P. The contribution of species-genetic diversity correlations to the understanding of community assembly rules. Oikos 126, 759771 (2017).

87. Labandeira, C. C. \& Sepkoski, J. J., Jr. Insect diversity in the fossil record. Science 261, 310-315 (1993).

88. Grimaldi, D., Engel, M. S., Engel, M. S. Evolution of the Insects. (Cambridge University Press, 2005).

89. Mitton, J. B. Selection in Natural Populations. (Oxford University Press, 2000).

90. Tajima, F. Evolutionary relationship of DNA sequences in finite populations. Genetics 105, 437-460 (1983).

91. Addo-Bediako, A., Chown, S. L. \& Gaston, K. J. Thermal tolerance, climatic variability and latitude. Proc. Biol. Sci. 267, 739-745 (2000).

92. Lawrence, E. R. \& Fraser, D. J. Latitudinal biodiversity gradients at three levels: Linking species richness, population richness and genetic diversity. Glob. Ecol. Biogeogr. 29, 770788 (2020).

93. Tougeron, K. Diapause research in insects: historical review and recent work perspectives. Entomol. Exp. Appl. 167, 27-36 (2019).

94. Danks, H. V. \& Others. The wider integration of studies on insect cold-hardiness. Eur. J. Entomol. 93, 383-404 (1996).

95. Du, C., Chen, J., Jiang, L. \& Qiao, G. High correlation of species diversity patterns between specialist herbivorous insects and their specific hosts. J. Biogeogr. 47, 1232-1245 (2020). 
96. Becerra, J. X. \& Lawrence Venable, D. Macroevolution of insect-plant associations: The relevance of host biogeography to host affiliation. Proc. Natl. Acad. Sci. U. S. A. 96, 12626-

97. Futuyma, D. J. \& Agrawal, A. A. Macroevolution and the biological diversity of plants and herbivores. Proc. Natl. Acad. Sci. U. S. A. 106, 18054-18061 (2009).

98. Schoonhoven, L. M., Van Loon, B., van Loon, J. J. A. \& Dicke, M. Insect-Plant Biology. (OUP Oxford, 2005).

99. Francis, A. P. \& Currie, D. J. A globally consistent richness-climate relationship for angiosperms. Am. Nat. 161, 523-536 (2003).

100.Kerkhoff, A. J., Moriarty, P. E. \& Weiser, M. D. The latitudinal species richness gradient in

101. Basset, Y. et al. Arthropod diversity in a tropical forest. Science 338, 1481-1484 (2012).

102. Barbour, M. A. et al. Multiple plant traits shape the genetic basis of herbivore community assembly. Funct. Ecol. 29, 995-1006 (2015).

103.Barbour, M. A. et al. Genetic specificity of a plant-insect food web: Implications for linking genetic variation to network complexity. Proc. Natl. Acad. Sci. U. S. A. 113, 2128-2133 (2016).

104. Janská, V. et al. Palaeodistribution modelling of European vegetation types at the Last Glacial Maximum using modern analogues from Siberia: Prospects and limitations. Quat. Sci. Rev. 159, 103-115 (2017).

105. Earl, C. et al. Spatial phylogenetics of butterflies in relation to environmental drivers and

884 106. Rix, M. G. et al. Biogeography and speciation of terrestrial fauna in the south-western 885 Australian biodiversity hotspot. Biol. Rev. Camb. Philos. Soc. 90, 762-793 (2015).

886 107.Myers, N., Mittermeier, R. A., Mittermeier, C. G., da Fonseca, G. A. B. \& Kent, J. 
Biodiversity hotspots for conservation priorities. Nature 403, 853-858 (2000).

108. Corser, J. D., White, E. L. \& Schlesinger, M. D. Odonata origins, biogeography, and diversification in an Eastern North American hotspot: multiple pathways to high temperate forest insect diversity. Insect Conserv. Divers. 7, 393-404 (2014).

109. Hawkins, B. A. \& DeVries, P. J. Tropical niche conservatism and the species richness gradient of North American butterflies. J. Biogeogr. 36, 1698-1711 (2009).

110. Tsutsui, N. D., Suarez, A. V., Holway, D. A. \& Case, T. J. Reduced genetic variation and the success of an invasive species. Proc. Natl. Acad. Sci. U. S. A. 97, 5948-5953 (2000).

111. Frankham, R. Resolving the genetic paradox in invasive species. Heredity 94, 385 (2005).

896 112.Keith, A. R., Bailey, J. K., Lau, M. K. \& Whitham, T. G. Genetics-based interactions of foundation species affect community diversity, stability and network structure. Proc. Biol. Sci. 284, (2017). heritability measures the evolutionary consequences of indirect genetic effects on community structure. Evolution 60, 991-1003 (2006). for linking genetic variation to network complexity. Proceedings of the (2016). consequences of intraspecific diversity: a meta-analysis. Biol. Rev. Camb. Philos. Soc. 94, 648-661 (2019).

116. Riggio, J. et al. Global human influence maps reveal clear opportunities in conserving Earth's remaining intact terrestrial ecosystems. Glob. Chang. Biol. (2020)

117. Hortal, J. et al. Seven Shortfalls that Beset Large-Scale Knowledge of Biodiversity. Annu. doi:10.1111/gcb.15109.

912 118. Coddington, J. A., Agnarsson, I., Miller, J. A., Kuntner, M. \& Hormiga, G. Undersampling 
bias: the null hypothesis for singleton species in tropical arthropod surveys. J. Anim. Ecol.

78, 573-584 (2009).

119.Leigh, D. M., Hendry, A. P., Vázquez-Domínguez, E. \& Friesen, V. L. Estimated six per cent loss of genetic variation in wild populations since the industrial revolution. Evol. Appl. 12, 1505-1512 (2019).

120. Teixeira, J. C. \& Huber, C. D. The inflated significance of neutral genetic diversity in conservation genetics. Proc. Natl. Acad. Sci. U. S. A. 118, (2021).

121.DeWoody, J. A., Harder, A. M., Mathur, S. \& Willoughby, J. R. The long-standing significance of genetic diversity in conservation. Molecular ecology vol. 30 4147-4154

122. García-Dorado, A. \& Caballero, A. Neutral genetic diversity as a useful tool for conservation biology. Conserv. Genet. 22, 541-545 (2021).

123. Reed, D. H. \& Frankham, R. Correlation between fitness and genetic diversity. Conserv. Biol. 17, 230-237 (2003).

124.Wilson, E. O. The little things that run the world* (the importance and conservation of invertebrates). Conserv. Biol. 1, 344-346 (1987).

125. Ratnasingham, S. \& Hebert, P. D. N. A DNA-based registry for all animal species: the barcode index number (BIN) system. PLoS One 8, e66213 (2013).

931 126. Sievers, F. et al. Fast, scalable generation of high-quality protein multiple sequence alignments using Clustal Omega. Mol. Syst. Biol. 7, 539 (2011).

127.Pallewatta, N., Reaser, J. K. \& Gutierrez, A. T. Invasive alien species in South-Southeast Asia: national reports and directory of resources. The Global Invasive Species Programme.

936 128. Hoban, S. et al. Genetic diversity targets and indicators in the CBD post-2020 Global

937 Biodiversity Framework must be improved. Biol. Conserv. 248, 108654 (2020).

938 129.Paz-Vinas, I. et al. Systematic conservation planning for intraspecific genetic diversity. 
Proc. Biol. Sci. 285, 20172746 (2018).

130. Nei, M. \& Li, W. Mathematical model for studying variation in terms of restriction endonucleases. Proc. Natl. Acad. Sci. U. S. A. 76, 5269-5273 (1979).

942 131. Gaggiotti, O. E. et al. Diversity from genes to ecosystems: A unifying framework to study 943 variation across biological metrics and scales. Evol. Appl. 11, 1176-1193 (2018).

944 132.Chao, A., Chiu, C.-H. \& Jost, L. Unifying Species Diversity, Phylogenetic Diversity,

945 Functional Diversity, and Related Similarity and Differentiation Measures Through Hill

$946 \quad$ Numbers. Annu. Rev. Ecol. Evol. Syst. (2014) doi:10.1146/annurev-ecolsys-120213-

947091540.

948 133. Alberdi, A. \& Gilbert, M. T. P. A guide to the application of Hill numbers to DNA-based

949 diversity analyses. Mol. Ecol. Resour. 19, 804-817 (2019).

950 134.Shannon, C. E. A mathematical theory of communication. The Bell System Technical

$951 \quad$ Journal 27, 379-423 (1948).

952 135. Hill, M. O. Diversity and Evenness: A Unifying Notation and Its Consequences. Ecology 54, $953 \quad$ 427-432 (1973).

954 136. Maurer, B. A. \& McGill, B. J. Measurement of species diversity. Biological diversity: frontiers 955 in measurement and assessment 55-65 (2011).

956 137. Chao, A. et al. Rarefaction and extrapolation with Hill numbers: a framework for sampling 957 and estimation in species diversity studies. Ecol. Monogr. 84, 45-67 (2014).

958 138. Welch, B. L. The Significance of the Difference Between Two Means when the Population 959 Variances are Unequal. Biometrika 29, 350-362 (1938).

960 139.Karger, D. N. et al. Climatologies at high resolution for the earth's land surface areas.

$961 \quad$ Scientific Data 4, 170122 (2017).

962 140.Brown, J. L., Hill, D. J., Dolan, A. M., Carnaval, A. C. \& Haywood, A. M. PaleoClim, high 963 spatial resolution paleoclimate surfaces for global land areas. Sci Data 5, 180254 (2018).

964 141.Tuanmu, M.-N. \& Jetz, W. A global, remote sensing-based characterization of terrestrial 
habitat heterogeneity for biodiversity and ecosystem modelling. Glob. Ecol. Biogeogr. 24, 1329-1339 (2015).

142.Kennedy, C. M., Oakleaf, J. R., Theobald, D. M., Baruch-Mordo, S. \& Kiesecker, J. Managing the middle: A shift in conservation priorities based on the global human modification gradient. Glob. Chang. Biol. 25, 811-826 (2019).

143.White, A. E., Dey, K. K., Mohan, D., Stephens, M. \& Price, T. D. Regional influences on 971 community structure across the tropical-temperate divide. Nat. Commun. 10, 2646 (2019).

972 144.Goodrich, B., Gabry, J., Ali, I. \& Brilleman, S. rstanarm: Bayesian applied regression 973 modeling via Stan. $R$ package version 2, 1758 (2018).

974 145.Piironen, J., Paasiniemi, M. \& Vehtari, A. Projective inference in high-dimensional

975 problems: Prediction and feature selection. EJSS 14, 2155-2197 (2020).

976 146. Legendre, P. \& Fortin, M. J. Spatial pattern and ecological analysis. Vegetatio 80, 107-138 (1989).

978 147.Bivand, R. S. \& Wong, D. W. S. Comparing implementations of global and local indicators of spatial association. Test $27,716-748$ (2018).

148. Carpenter, B. et al. Stan: A Probabilistic Programming Language. Journal of Statistical Software, Articles 76, 1-32 (2017).

982 149.Stan Development Team. RStan: the R interface to Stan. (2020).

983 150.Gimenez, O., Morgan, B. J. T. \& Brooks, S. P. Weak Identifiability in Models for Mark984 Recapture-Recovery Data. in Modeling Demographic Processes In Marked Populations 985 (eds. Thomson, D. L., Cooch, E. G. \& Conroy, M. J.) 1055-1067 (Springer US, 2009). 986 doi:10.1007/978-0-387-78151-8_48.

987 151.Elith, J., Kearney, M. \& Phillips, S. The art of modelling range-shifting species. Methods $988 \quad$ Ecol. Evol. 1, 330-342 (2010). 


\section{Acknowledgements}

990 We thank Jason L Brown for his valuable feedback on early drafts of the manuscript, and the

991 Hickerson and Carnaval labs for their feedback at every step of the project. CMF, MJH, ACC, IO

992 and AR acknowledge support from NSF DBI 2104147 and the NSF RCN Cross-Scale

993 Processes Impacting Biodiversity (DEB 1745562). DJL was funded by NSF DEB-1541557.

994

995 Author contributions

996 C.M.F., L.D.B., and M.J.H. conceived of the study. C.M.F., L.D.B., J.M.K., K.A.M., I.O., A.R.,

997 P.S., A.C.C., and M.J.H. framed the study. C.M.F., L.D.B., and M.J.H. carried out the analyses.

998 C.M.F., and M.J.H. led the writing. All authors contributed to interpretation of the results and to

999 the writing, and all have approved the submission. A.R. and P.S. contributed to Figure 1.

1000 Competing interests

1001 The authors declare no competing interests.

1002 